\title{
Molecular analysis supports controversial claim for dinosaur cells
}

\author{
New evidence adds heat to the argument over prehistoric dinosaur tissue.
}

\section{Kate Wong}

22 October 2012

\section{An article by Scientific American.}

RALEIGH—Twenty years ago, paleontologist Mary Schweitzer made an astonishing discovery. Peering through a microscope at a slice of dinosaur bone, she spotted what looked for all the world like red blood cells. It seemed utterly impossibleorganic remains were not supposed to survive the fossilization process—but test after test indicated that the spherical structures were indeed red blood cells from a 67-million-year-old Tyrannosaurus rex. In the years that followed, she and her colleagues discovered other apparent soft tissues, including what seem to be blood vessels and feather fibers. But controversy accompanied their claims. Skeptics argued that the alleged organic tissues were instead biofilm—slime formed by microbes that invaded the fossilized bone.

Schweitzer and her colleagues have continued to amass support for their interpretation. The latest evidence comes from a molecular analysis of what look to be bone cells, or osteocytes, from T. rex and Brachylophosaurus canadensis. The researchers isolated the possible osteocytes and subjected them to several tests. When they exposed the cell-like structures to an antibody that targets a protein called PHEX found only in bird osteocytes* (birds are descended from dinosaurs), the structures reacted, as would be expected of dinosaur osteocytes. And when the team subjected the supposed dinosaur cells to other antibodies that target DNA, the antibodies bound to material in small, specific regions inside the apparent cell membrane.

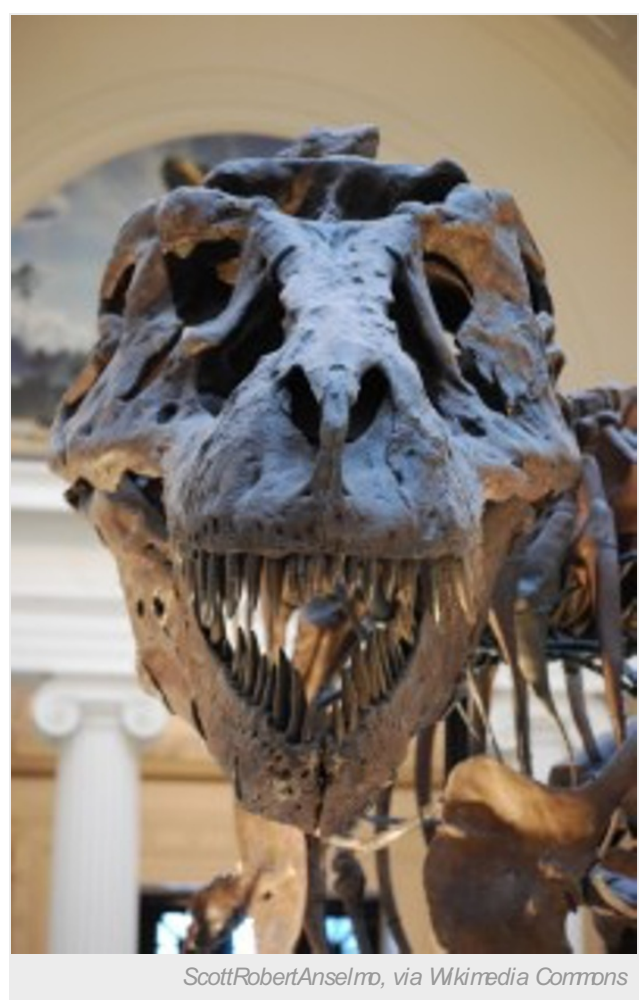

Do fossils of dinosaurs, such as Tyrannosaurus rex, contain soft tissues?

Furthermore, using a technique called mass spectrometry, the investigators found amino acid sequences of proteins in extracts of the dinosaur bone that matched sequences from proteins called actin, tubulin and histone4 that are present in the cells of all animals. Although some microbes have proteins that are similar to actin and tubulin, the researchers note that soil-derived E. coli as well as sediments that surrounded the two dinosaur specimens failed to bind to the actin and tubulin antibodies that bound to the extract containing the apparent osteocytes.

Schweitzer and her collaborators detailed their findings in a paper released online October 16 in the journal Bone and in a talk given October 17 in Raleigh at the annual meeting of the Society of Vertebrate Paleontology. "Here's the data in support of a biofilm origin," Schweitzer said in her presentation as she showed a blank slide. "We haven't found any yet."

SCIENTI IC *Update, Oct. 20, 2012, 11:24 a.m.: Mary Schweitzer emailed me to clarify a point that did not come AMLRTCA ther the across in her talk. "PHEX is actually found in many taxa. However proteins have thousands of More from Scientific American. antibody binding sites on them. Some antibodies that bind to epitopes shared among groups are broadly cross reactive. Ours, OB 7.3 was selected for only one epitope out of thousands, and that epitope is, so far as it has been tested by the primary researchers, only reactive to osteoctyes from birds. It has been tested against bird osteoblasts, cells on the same lineage as osteocytes, and does not react, and it does not react with osteocytes from non avian taxa tested. So it is the selective specificity of the antibody for bird osteocytes that is important. We are not saying birds and dinos are the only ones that have the protein, but because the sequence is inherited, it has different 'shapes' in each group and the 'shape' this antibody binds seems to be unique to bird osteocytes in living taxa." 